\title{
NOVO PROCESSO DE CUMPRIMENTO DE SENTENÇA: UMA VISÃO CRÍTICA E DINÂMICA ${ }^{1}$ \\ Rodolfo Kist de Mello²
}

RESUMO: As novas alterações do CPC representam um avanço no sentido da perspectiva da satisfação do direito material nas ações judiciais. Entretanto, podem causar erros doutrinários relativos à classificação e à natureza da nova abordagem da sentença executiva e, até mesmo, desclassificar toda a técnica que envolve a atividade do Advogado com a fantasia da ausência dos honorários na fase de cumprimento de sentença.

PALAVRAS-CHAVE: Sincretismo, sentença executiva, unificação procedimental, honorários.

\section{New Process of Execute Sentence: A Critic and Dynamic Vision}

ABSTRACT: The new alterations from CPC portray an advance in the meaning of material law satisfaction perspective in judicial actions. Therefore, they may cause doctrine errors related to classification and nature of the executive sentence new aboarding and moreover disclassificate the hole technique that involves lawyer's work and the fantasy of payment absence on sentence execution stage.

KEY-WORDS: Syncretism, executive sentence, proceeding unification, payment.

\section{INTRODUÇÃO}

A nova busca pela real efetivação dos anseios sociais junto ao judiciário é importante, mas é necessário que se criem mecanismos que realmente atuem na realização dos direitos materiais e não extrapolem a segurança jurídica das relações processuais e garantam a manutenção da paz social.

\section{A VISÃO PRELIMINAR DO CONCEITO DE SENTENÇA}

A definição trazida pela antiga redação do artigo $162, \S 1^{\circ}$ fornecia uma visão tautológica - vício de linguagem que consiste em dizer, por formas diversas, sempre a mesma coisa - da sentença. Ocorre que ao definir sentença como o ato que dá termo ao processo, a doutrina obtém uma resposta imprecisa e simplesmente geográfica, ficando ainda mais evidente a errônea definição ao ser formulada a pergunta: "qual é o ato que dá fim ao processo?", desta se extraí a sentença como resposta, consagrando a ciência puramente tautológica de sua definição.

\footnotetext{
${ }^{1}$ Traz uma abordagem dinâmica sobre as alterações no processo de execução, levantando temas para um pensamento crítico a doutrina típica do cumprimento de sentença.

${ }^{2}$ Acadêmico do 9o Semestre do Curso de Direito da UFSM. E-mail: rodokist@ gmail.com.
}

ISSN - 1981-3694

(C) 2007. Departamento de Direito da UFSM. Todos os direitos reservados. 
Ovídio Baptista (1979 apud OVÍDIO BAPTISTA, 2005, p. 381) leciona que a análise simplória do conceito de sentença pode resultar em uma concepção equivocada, visto que esta traz duas interpretações à sua regra: a) declarar de modo irrevogável e definitivo o direito aplicável ao litígio (sendo definitivas as sentenças que somente analisarem o mérito) ou b) estabelecer um critério geográfico (tipológico), sendo que a sentença - é o caso da que indefere a petição inicial, ensejando assim a necessidade de a via recursal a atacar este indeferimento ser a apelação - seria a demarcação final do litígio.

Construiu-se então um entendimento doutrinário no sentido de que o conceito de sentença se inclinaria àquela interpretação. Araken de Assis (2004, p.433) se posiciona no sentido que "pôr termo ao processo não é essência da sentença. É um efeito seu."

Conclui então, Ovídio Baptista (2005, p. 381) que "o conceito de sentença como ato final por meio do qual o juiz encerra o processo, circunstância que, como se viu e melhor verá ao examinar as ações executivas e mandamentais, nem sempre acontece."

Ensejando um clamor por reformas, desde a esfera social até o âmbito dos exegetas no direito para assim, se buscar uma prestação jurisprudencial mais efetiva e célere. Nesse sentido afirma Humberto Theodoro Júnior:

"Daí por que as últimas e mais profundas reformas do processo civil têm se voltado para as vias de execução civil. Seu maior objetivo tem sido, nessa linha, a ruptura com figuras e praxes explicáveis do passado, mas completamente injustificáveis e inaceitáveis dentro das perspectivas sociais e políticas que dominam o devido processo legal em sua contemporânea concepção do processo justo e efetivo.

É o caso da dualidade de processos que teima em tratar como objeto de ações distintas e completamente separadas o acertamento e a execução dos direitos subjetivos violados, com a perda de tempo e acréscimo de custos, incompatíveis com a efetividade esperada da tutela jurisdicional."

Analisar a estrutura lógica da sentença não será tratado, não que seja merecedor de descaso, mas simplesmente por não ser o objeto do presente estudo, sendo este a nova abordagem da sentença executiva latu sensu.

\section{A NOVA ABORDAGEM DAS SENTENÇAS EXECUTIVAS LATU SENSU}

\footnotetext{
${ }^{3}$ THEODORO JÚNIOR, Humberto. As vias de execução do Código de Processo Civil Brasileiro reformado.In: BRÊTAS C. DIAS, Ronaldo; NEPOMUCENO, Luciana Diniz (Coords.). Processo Civil Reformado. Belo Horizonte: Del Rey, 2007, p.43-44
} 
Entendemos os anseios sociais em relação à morosidade judiciária e a necessidade do Judiciário efetivar medidas racionais e eficientes para solucionar ou, na pior das hipóteses, atenuar a crítica situação jurídico-social em que se encontram as prestações jurisdicionais brasileiras. As ondas reformistas sempre tiveram uma grande evolução no que tange à eficiência de suas alterações, sendo como exemplos clássicos a antecipação de tutela (art. 273 do CPC) e a criação do art. 461 - A para a tutela específica da obrigação de entregar coisa.

Através da vanguarda legislativa, com a lei 11.232, se almeja obter uma mais célere satisfação do crédito por parte do credor, oportunizando para este, através de requerimento, que peticione a obtenção da execução deste título judicial nos próprios autos do processo de cognição.

Não raros são os doutrinadores que se referem a esta situação como sentenças executivas latu sensu para designar espécie - por se tratar de uma mera petição para o seguimento do feito, antes cognitivo, agora executivo - mas erroneamente a tratam. Seguindo a corrente de Pontes de Miranda (1974 apud WAMBIER, 2006, p. 81), as sentenças executivas latu sensu são gênero, das quais fazem parte: a) ação executiva, por antecipação ou adiantamento da executividade, de que são exemplos as ações de títulos extrajudiciais, mas de cognição incompleta ao tempo da eficácia executiva; b) ação executiva, sem antecipação ou adiantamento da executividade, de modo que a sentença final é a "executiva"; c) ação executiva de sentença (execução de sentença), que são títulos para se iniciar execução, já sem a elaboração de cognição completa, porque a sentença exeqüenda deixou atrás aquela elaboração e tende a explorar a cognição completa que traz em si.

Athos Gusmão Carneiro, que foi um dos mentores da reforma que será brevemente analisada, afirma que "a expressão 'do cumprimento da sentença' revela, pois com mais precisão, a meta desta última fase do processo de conhecimento". 4

\subsection{A nova definição de sentença e suas críticas}

A natureza da sentença que pronuncia o direito do credor em um título executivo, resolvendo o mérito, é uma sentença condenatória (em sua maior eficácia, segundo a carga da eficácia preponderante) dependendo de requerimento do credor para

${ }^{4}$ CARNEIRO, Athos Gusmão. Nova Execução. Aonde vamos? Vamos melhorar. Revista de Processo n. 123. p. 116. 
que o título seja executado, não lhe sendo atribuída uma auto-executividade, como a doutrina considera.

Esta percepção equivocada se deve à incidência da multa de $10 \%$ sobre o montante devido, dado o inadimplemento do devedor, se passados 15 dias.

A natureza da multa indenizatória deve ser entendida de forma independente, através da auto-aplicação, como ocorre em um contrato de aluguel em que o inadimplemento faz incidir automaticamente a multa, mas depende de uma execução para se obter o crédito (apesar de ser extrajudicial).

No entanto, a necessidade de requerimento para prosseguir o pleito executivo somente dá sincretismo ao cumprimento de sentença (verifica-se assim, a quebra do princípio da autonomia processual entre o processo de conhecimento e o de execução), pois a relação processual já está formada e angularizada desde a citação válida do procedimento cognitivo, bastando ao credor mero requerimento para seguir no procedimento executório.

Cabe ainda uma análise do art. $162 \S 1^{\circ}$, que traz um novo conceito para a sentença:

$\S 1^{o}$ Sentença é o ato do juiz que implica algumas das situações previstas nos atrs. 267 e 269 desta lei. (grifamos)

A nova redação repara impropriedades que a redação anterior possuía, principalmente ao retirar o critério topológico, mas não está livre de críticas.

Pode se verificar que a palavra grifada acima (algumas) não restringe a todas as possibilidades dos artigos 267 e 269, deixando vagas quais situações não se enquadrariam como sentença, se é que isto ocorreria. Creio que se deveria ter a redação de "algumas" substituída pelas palavras "uma", pois assim taxaria o rol das possibilidades de sentença a todas as situações referidas naqueles artigos, sem a possibilidade de excluir alguma situação devido a erro de redação.

Giuseppe Chiovenda (1998) sustenta a proposta de que o conceito de sentença definitiva seria a sentença que se pronuncia sobre a demanda judicial, acolhendo-a, rejeitando-a ou declarando não poder decidir sobre ela.

Ainda sobre a questão topológica da sentença, esta tecnicamente é o ápice do desenvolvimento estrutural de um processo, através do qual diversos atos se realizam, não necessitando terminar com a sentença. Veja-se o caso da ação de reintegração de posse, na qual a decisão que determina a tutela pretendida na inicial - a retomada da 
posse pelo possuidor esbulhado - será efetuada após o proferimento da sentença. Assim, esta não exaurirá, muito menos dará termo ao processo, mas será uma etapa importantíssima dentro da cadeia de atos de um processo até a realização material do pedido do autor.

Logo, ao determinar que a sentença não dá termo ao processo, permite-se que no mesmo processo se realizem atos necessários para efetivar os fins da demanda postada em direito material, o que acontece de forma semelhante entre a natureza das obrigações do 461 do CPC com as do art. 475 - J, e da natureza da sua multa pelo inadimplemento.

Entretanto, a busca pela adequação da nova sentença pode trazer a conclusões precipitadas do 475 - J nas obrigações de pagar quantia certa. Sabe-se que a sentença proferida neste procedimento sincrético tem natureza condenatória, pois condena o réu ao pagamento de determinada quantia. Entretanto, existe o pensamento que esta sentença teria a carga executiva, esta em escala imediata - com a incidência da multa de $10 \%$ - e em escala mediata, a execução propriamente dita à obrigação que condena o devedor.

Erram grosseiramente ao fazer esta percepção por considerar que pela mudança principiológica (da autonomia dos processos de execução e do conhecimento para o sincretismo entre ambos os processos) modifica-se também a carga de eficácia da sentença.

Com o sincretismo entre a cognição e a execução somente se objetivou o auxílio aos fins pretendidos, ou seja, o direito processual precisa estar em consonância com os direitos materias vinculados nas demandas judiciais. Sendo assim, com a sentença que obriga o réu a pagamento de quantia certa, nada mais coerente que se agilizar o meio para se obter a realização do pagamento, ou seja, a execução.

É através desse mecanismo adotado pela terceira onda reformista do CPC - o Sincretismo - que se obtém, de uma forma mais célere, os fins pretendidos com a demanda iniciada.

\subsection{Como o art. 463 deve ser utilizado}

A nova redação do artigo 463 do CPC menciona que, publicada a sentença, o juiz só poderá alterá-la: a) para corrigir, de ofício ou a requerimento da parte, inexatidões materiais; b) retificar erros de cálculo; c) por meio de embargos de declaração. É importante salientar que a atividade do magistrado na nova visão sincrética do processo civil não é discricionária, e nem poderia ser. 
Ao retirar a autonomia do processo de execução em relação ao processo de cognição deve-se lembrar que a atividade jurisdicional do magistrado se exaure com o prazo em branco do trânsito em julgado da sentença, e se inicia a fase de execução com o requerimento da parte credora. Óbvio então, que o magistrado, durante a fase de cumprimento de sentença, não poderá acrescer novos dispositivos na sentença já publicada, conforme corrobora entendimento do STJ:

Decisão em que juiz acrescenta novo dispositivo a sentenca já publicada. Tal decisão não é ato judicial, pois o magistrado já exauriu e acabara seu ofício jurisdicional (CPC, art. 463). Nela se contém ato administrativo emanado de autoridade incompetente. Contra ela cabe mandado de segurança, independentemente de recurso preparatório. (STJ - RT 699/173). (grifamos)

Portanto, é com bons e prudentes olhos que se deve verificar a atividade do magistrado na nova fase de cumprimento de sentença, evitando arbítrios por parte deste e violações a legítima defesa.

\section{DOS HONORÁRIOS NO SINCRETISMO PROCESSUAL}

Determinado pela alteração da lei 11.232 , a unificação procedimental entre o processo de conhecimento e processo de execução traz benefícios, além da celeridade, que é a ausência da necessidade de pagamento das custas processuais, visto que para o início da execução é necessário um requerimento, não necessitando nova citação.

Do sincretismo das reformas é imperativo salientar que permanece a necessidade de defesa técnica, pois o requerimento para seguir a execução deve ser feito por advogado com procuração no processo de conhecimento. Dessa forma, são devidos honorários advocatícios com aplicação do artigo $20 \S 4^{\circ}$ do CPC, que dispõe:

"Nas causas de pequeno valor, nas de valor inestimável, naquelas em que não houver condenação ou for vencida a Fazenda Pública, e nas execucões, embargadas ou não, os honorários serão fixados consoante apreciação eqüitativa do juiz, atendidas as normas das alíneas $a, b$ e $c$ do parágrafo anterior.” (grifamos)

Os honorários aludidos no segmento acima referem-se tanto à aplicação na execução judicial quanto na extrajudicial, independentemente da autonomia ou do sincretismo processual. Logo, estes são devidos também na fase de cumprimento de sentença após o requerimento para dar seguimento ao feito. 
O Superior Tribunal de Justiça se posicionou em conformidade com esta visão, acabando com uma celeuma que pairava sobre este tema:

Execução. Honorários de advogado. Art. 20, \$4º , do Código de Processo Civil com a redação dada pela Lei no 8.952/94.

1. A nova redação do art. 20, do Código de Processo Civil deixa induvidoso cabimento de honorários de advogado em execução, mesmo não embargada. Não fazendo a lei, para esse fim, distinção entre execução fundada em titulo judicial e execução fundada em titulo extrajudicial. (STJ, REsp $\mathrm{n}^{\circ}$ 140.403/RS, Min. Rel. Carlos Alberto Menezes Direito, j. 07/10/1998, DJ. 05/04/1999)

Poder-se-ia tentar mencionar que esta decisão seria anterior as reformas (em especial a lei 11.232/05), e que sua aplicação estaria defasada, mas isto não ocorre. A redação do artigo 475-R traz que as normas que regem a execução de título extrajudicial serão aplicadas subsidiariamente no cumprimento de sentença. Conjugando-se a este o artigo 710 do CPC, que menciona que só será restituído ao devedor o que sobrar do pagamento ao devedor o que sobrar do pagamento do principal, juros, custas e honorários.

Nelson Nery Júnior e Rosa Maria de Andrade Nery se posicionam com o referido entendimento:

A incidência dos honorários ocorre pelo simples fato de haver execução de sentença, ainda que não impugnada ou embargada. Nos casos de cumprimento da sentença, nos termos do CPC 475-I a 475-R, incluídos pela Lei 11.232/05, além da multa de $10 \%$ sobre o valor da condenação, prevista para a hipótese de não cumprimento imediato da sentença transitada em julgado (CPC, 475-J) são devidos honorários de advogado."5

Vale lembrar que o artigo 133 da Constituição Federal traz o advogado como função indispensável à administração da justiça, o que ressalta ainda mais a posição de serem devidos os honorários na presente discussão.

Inequívoco é então, que a remuneração do advogado deverá ser fixada de modo proporcional à atividade desenvolvida pelo procurador tanto na fase de conhecimento quanto na fase de cumprimento da sentença.

\section{5.. CONSIDERAÇÕES FINAIS}

\footnotetext{
${ }^{5}$ NERY JÚNIOR, Nelson;NERY, Rosa Maria de Andrade Nery. Código de Processo Civil Comentado. São Paulo: Editora Revista dos Tribunais, 2006, p. 194
} 
De todo o exposto, fica a situação da necessidade de manter as reformas processuais a fim de continuar na evolução para um direito processual civil mais coerente com seus fins e atento a realidade morosa do nosso judiciário.

Entretanto, as alterações necessitam de um olhar detalhado e adequado, não a simples aplicação sem atender a totalidade do ordenamento jurídico, sendo imprescindível a sua aplicação conforme todo o direito, não simplesmente se aplicar regras esparsas, mitigando assim o exercício da advocacia.

A pesquisa simplesmente trouxe a tona aspectos não usuais das reformas, mas que merecem abordagem e uma opinião para não ficarmos a mercê de entendimentos simplistas.

\section{REFERÊNCIAS BIBLIOGRÁFICAS}

Assis, Araken de. Manual de Processo de Execução. São Paulo. RT, 2004.

Baptista da Silva, Ovídio A. Curso de Processo Civil. Rio de Janeiro, Forense, 2005.

CARNEIRO, Athos Gusmão. Nova Execução. Aonde vamos? Vamos melhorar. Revista de Processo n. 123.

Chiovenda, Giusseppe. Instituições de direito processual civil. Campinas: Bookseller, 1998

NERY JÚNIOR, Nelson;NERY, Rosa Maria de Andrade Nery. Código de Processo Civil Comentado. $9^{\mathrm{a}}$ ed. São Paulo: Editora Revista dos Tribunais, 2006.

THEODORO JÚNIOR, Humberto. As vias de execução do Código de Processo Civil Brasileiro reformado.In: BRÊTAS C. DIAS, Ronaldo; NEPOMUCENO, Luciana Diniz (Coords.). Processo Civil Reformado. Belo Horizonte: Del Rey, 2007.

Wambier, Luiz Rodrigues org. Breves Comentários à Nova Sistemática Processual Civil. São Paulo: RT, 2006. 